\title{
Qualidade de mandioquinha-salsa minimamente processada e armazenada sob atmosfera modificada
}

\author{
Quality of fresh-cut peruvian carrot: use of modified atmosphere
}

\author{
Elisângela Elena Nunes ${ }^{\mathrm{I}}$ Eduardo Valério De Barros Vilas Boas ${ }^{\mathrm{II}}$ \\ Andréa Luiza Ramos Pereira Xisto ${ }^{\text {II }}$ Brígida Monteiro Vilas Boas ${ }^{\text {III }}$
}

\section{RESUMO}

O objetivo deste trabalho foi verificar o efeito da atmosfera modificada, passiva e ativa, sobre a conservação de mandioquinha-salsa minimamente processada da cultivar 'Amarela de Senador Amaral', adquirida de lavoura comercial do Município de Lavras, Minas Gerais (MG). As raízes foram selecionadas, lavadas com detergente neutro e enxaguadas em água corrente. Em seguida, foram imersas em solução de hipoclorito de sódio $300 \mathrm{mg} \mathrm{L}^{-1}$, por 15 minutos, e secas em temperatura ambiente. As raízes foram descascadas e cortadas em fatias de aproximadamente $1 \mathrm{~cm}$ de espessura, imersas em solução de hipoclorito de sódio $50 \mathrm{mg} \mathrm{L}^{-1}$, por 10 minutos, drenadas em peneiras plásticas e embaladas. As bandejas contendo as fatias de mandioquinha-salsa foram armazenadas em câmara fria $\left(5 \pm 1^{\circ} \mathrm{C}\right.$ e $98 \%$ UR) por 15 dias. As seguintes análises foram realizadas a cada três dias: $p H$, acidez titulável, sólidos solúveis totais, firmeza, valores $L^{*} e b^{*}$, amido $e$ avaliação sensorial (aparência e cor). O delineamento experimental foi inteiramente ao acaso (DIC), em esquema fatorial $3 \times 6$, sendo três tipos de atmosferas (passiva; ativa com injeção inicial das misturas: $2 \% \mathrm{O}_{2}+10 \% \mathrm{CO}_{2}$ e $5 \% \mathrm{O}_{2}$ $\left.+5 \% \mathrm{CO}_{2}\right)$ e seis tempos de armazenamento $(0,3,6,9,12$ e 15 dias), com três repetições. Os valores médios de $\mathrm{pH}$, acidez titulável, sólidos solúveis e firmeza encontrados neste trabalho foram $6,79,0,13 \%$ de ácido málico, $4,04^{\circ} \mathrm{Brix}$ e 5,17N, respectivamente. A atmosfera modificada ativa $\left(5 \%\right.$ de $\mathrm{O}_{2}+$ $5 \% \mathrm{CO}_{2}$ ) determinou maior valor $L^{*}$ às mandioquinhas-salsa minimamente processadas no sexto e no décimo segundo dia de armazenamento, quando comparada com a atmosfera (2\% de $\mathrm{O}_{2}$ e $10 \% \mathrm{CO}_{2}$ ). A atmosfera modificada ativa com $5 \% \mathrm{O}_{2}+$ $5 \% \mathrm{CO}_{2}$ determinou maiores valor $b^{*}$ e teores de amido às fatias de mandioquinha-salsa em comparação com as outras atmosferas. Conclui-se que a atmosfera modificada passiva, aliada à refrigeração e a boas práticas de fabricação, é suficiente para prolongar a vida útil de mandioquinhas-salsa minimamente processadas, preservando seus atributos de qualidade. Diante da avaliação sensorial realizada, a aparência e a cor das fatias de mandioquinha-salsa mantiveram-se aceitáveis para o consumo até o final do período de armazenamento.

Palavras-chave: armazenamento, processamento mínimo, embalagem.

\section{ABSTRACT}

The aim of this research was to verify the effect of the passive and active modified atmosphere on the conservation of fresh-cut peruvian carrot, cv. Amarela de Senador Amaral, purchased from a commercial crop of Lavras, MG, Brazil. The roots were screened, washed with neutral detergent and rinsed in running water. Afterwards, they were immersed into a solution of $300 \mathrm{mg} \mathrm{L}^{-1}$ sodium hypochlorite for 15 minutes and dried at room temperature. The roots were peeled and cut in slices of about $1 \mathrm{~cm}$ of thickness and immersed into a solution of $50 \mathrm{mg}$ $L^{-1}$ sodium hypochlorite for 10 minutes, drained in plastic sieves and packed. The trays containing the slices of Peruvian carrot were stored in a cold room $\left(5 \pm 1^{\circ} \mathrm{C}\right.$ and $\left.98 \% \mathrm{RH}\right)$ for 15 days. The following analyses were performed every 3 days: : $p H$, titrable acidity, total soluble solids, firmness, $L^{*}$ and $b^{*}$ values, starch and sensorial evaluation (appearance and color). The experimental design was completely randomized (CRD) in a 3 $x 6$ factorial scheme, with 3 sorts of atmospheres (passive; active with initial injection of the mixtures: $2 \% \mathrm{O}_{2}+10 \% \mathrm{CO}_{2}$ e $\left.5 \% \mathrm{O}_{2}+5 \% \mathrm{CO}_{2}\right)$ and 6 times of storage $(0,3,6,9,12$ and 15 days) with 3 replicates. The average values of $\mathrm{pH}$, titrable acidity, soluble solids and firmness found in this work were $6.79,0.13 \%$ of malic acid, $4.04^{\circ} \mathrm{Brix}$ and $5.17 \mathrm{~N}$, respectively. The active modified atmosphere (5\% de $\left.\mathrm{O}_{2}+5 \% \mathrm{CO}_{2}\right)$ determined higher $L^{*}$ value to the fresh cut Peruvian carrots at the sixth and twelfth day of storage as compared with the active $\left(2 \%\right.$ of $\left.\mathrm{O}_{2}+10 \% \mathrm{CO}_{2}\right)$. The active modified atmosphere with $5 \% \mathrm{O}_{2}+5 \% \mathrm{CO}_{2}$ determined higher $b^{*}$ values and starch contents to the slices of Peruvian carrots as compared with the other atmospheres. It can be concluded that the passive modified

'Centro Universitário UNIRG, 77435-100, Gurupi, TO, Brasil. E-mail: elisanunescarvalho@hotmail.com. Autor para correspondência.

IIUniversidade Federal de Lavras (UFLA), Lavras, MG, Brasil.

IIIInstituto Federal de Educação, Ciência e Tecnologia do Sul de Minas Gerais, Campus Machado, Machado, MG, Brasil. 
atmosphere associated with refrigeration and good practices of manufacture is enough to extend the shelf life of fresh cut Peruvian carrots, keeping their quality attributes. In accord to the sensorial evaluation, both appearance and color of the slices of Peruvian carrots are kept acceptable for consumption until the end of the storage period.

Key words: storage, fresh-cut, packing.

\section{INTRODUÇÃO}

A mudança nos padrões de consumo de alimentos tem levado ao maior consumo de frutas e hortaliças em detrimento dos produtos industrializados. Ao mesmo tempo, os consumidores desejam produtos com qualidade e praticidade. Nesse sentido, a demanda por frutas e hortaliças minimamente processadas tem evoluído rapidamente (ARRUDA et al., 2004).

O elevado preço de venda de mandioquinhasalsa a granel, em supermercados e em outros pontos de comercialização, está relacionado com o fato de a cultura possuir ciclo vegetativo longo, baixa produtividade em algumas regiões produtoras, além de baixa conservação pós-colheita, quando comparada com outras hortaliças. O processamento mínimo dessa hortaliça, ao agregar valor ao produto, contribui ainda mais para a sua valorização (MORETTI \& ARAÚJO, 2001).

Apesar de o consumo dessa hortaliça na forma minimamente processada estar crescendo, observa-se que ainda existem fatores limitantes para sua produção, os quais são impostos pelo seu elevado grau de perecibilidade. Para tornar esse tipo de alimento menos perecível, destaca-se o uso da atmosfera modificada associada à refrigeração.

A atmosfera modificada é usada comercialmente para suprimir o crescimento de microrganismos e estender a vida útil de produtos vegetais. A atmosfera modificada pode ser passiva, em que as embalagens são seladas no ar, ou ativa, em que uma mistura definida de gases é injetada na embalagem, tipicamente com oxigênio $\left(\mathrm{O}_{2}\right)$ reduzido e dióxido de carbono $\left(\mathrm{CO}_{2}\right)$ aumentado. A principal vantagem da atmosfera modificada ativa está na rapidez com que a atmosfera desejada é estabelecida.

Quando a atmosfera modificada é associada à refrigeração, há substancial redução no crescimento microbiano, e mudanças químicas e fisiológicas podem ser retardadas (PIROVANI, 1998). Cada produto apresenta uma determinada atmosfera de acondicionamento específica e adequada e dependente da temperatura e do período de estocagem (DAREZZO, 2000). O controle da temperatura e das boas condições sanitárias é imprescindível para o sucesso da tecnologia. Assim, tratamentos fitossanitários e processos adequados de higienização devem ser aplicados aos produtos hortícolas que serão embalados sob atmosfera modificada (SANTOS \& VALLE , 2005).

Além dos defeitos visuais, algumas alterações no sabor podem ser induzidas, aplicando atmosfera modificada (HEIMDAL et al., 1995; BEAUDRY, 2000) e/ou crescimento microbiano (CARLIN et al., 1989; LOPEZ-GALVEZ et al., 1997). Por exemplo, a exposição a níveis elevados de $\mathrm{CO}_{2}(10-$ $20 \%$ ) pode resultar na supressão de vários processos metabólicos. Entretanto, na presença do $\mathrm{O}_{2}$ suficiente, a qualidade sensorial é menos afetada (KAYS, 1991; MATHOOKO, 1996; LOPEZ-GALVEZ et al., 1997; WATKINS, 2000). O desenvolvimento de aromas indesejáveis em vegetais minimamente processados pode também ser provocado pela falta do $\mathrm{O}_{2}$, e as atmosferas anaeróbicas podem provocar metabolismo fermentativo (KADER et al., 1989; KAYS, 1991; BEAUDRY, 2000). A severidade de produção de offflavor dependerá do tempo de exposição abaixo da concentração mínima requerida de $\mathrm{O}_{2}$ e/ou acima da concentração máxima tolerada de $\mathrm{CO}_{2}^{2}$ (BEAUDRY, 2000; WATKINS, 2000).

A escassez de trabalhos publicados sobre o tema atesta a necessidade de estudos sobre a conservação da mandioquinha-salsa minimamente processada e fez com que o objetivo deste trabalho fosse verificar o efeito de diferentes concentrações de $\mathrm{CO}_{2}$ e $\mathrm{O}_{2}$ sobre o comportamento pós-colheita desse produto minimamente processado.

\section{MATERIAL E MÉTODOS}

As mandioquinhas-salsa da cultivar 'Amarela de Senador Amaral' foram adquiridas de uma lavoura comercial do Município de Lavras, Minas Gerais (MG), e transportadas para o Laboratório de Póscolheita de Frutas e Hortaliças do Departamento de Ciência dos Alimentos da Universidade Federal de Lavras (UFLA). Em seguida, foram selecionadas, lavadas com detergente neutro e enxaguadas em água corrente, para remoção de sujeiras do campo; imersas em solução de hipoclorito de sódio $300 \mathrm{mg} \mathrm{L}^{-1}$ por 15 minutos e secas em temperatura ambiente. As raízes foram descascadas e cortadas em fatias de aproximadamente $1 \mathrm{~cm}$ de espessura, imersas em solução de hipoclorito de sódio $50 \mathrm{mg} \mathrm{L}^{-1}$ por 10 minutos e drenadas em peneiras plásticas, para retirada do excesso de líquido.

Ciência Rural, v.39, n.7, out, 2009. 
Depois de realizado o processamento, as fatias de mandioquinha-salsa foram acondicionadas em bandejas de polipropileno ( 15 x 11,5 x 4,5cm), seladas em seladora de bandejas modelo AP340 - Tecmaq com filme de polietileno + polipropileno $(60 \mathrm{~mm}$ de espessura), fazendo uso de injeção de gases para obtenção inicial de atmosfera modificada. Os tratamentos foram dispostos seguindo um esquema fatorial $3 \times 6$, sendo constituídos pelas combinações das diferentes atmosferas modificadas: atmosfera modificada passiva ou controle (sem injeção de gases); atmosferas modificadas ativas com injeção inicial das seguintes misturas comerciais de gases: $10 \% \mathrm{CO}_{2}+$ $2 \% \mathrm{O}_{2}$ e $5 \% \mathrm{CO}_{2}+5 \% \mathrm{O}_{2}$. As bandejas contendo os produtos minimamente processados foram armazenadas em câmara fria $\left(5 \pm 1^{\circ} \mathrm{C}\right.$ e $98 \%$ UR) por 15 dias. A cada três dias foram realizadas as seguintes análises: o pH foi medido em potenciômetro, segundo a técnica da AOAC (1992); a acidez titulável (\% de ácido málico) foi determinada por titulação com solução padronizada de $\mathrm{NaOH} 0,01 \mathrm{~N}$, de acordo com as normas do INSTITUTO ADOLFO LUTZ (1985); os sólidos solúveis ( ${ }^{\circ} \mathrm{Brix}$ ) foram determinados por refratometria, segundo AOAC (1992); a firmeza (N) foi determinada com auxílio de um analisador de textura modelo TA.XT2i, utilizando uma sonda de aço inoxidável de $2 \mathrm{~mm}$ de diâmetro $(\mathrm{P} / 2 \mathrm{~N})$, velocidade de $5 \mathrm{~mm} \mathrm{~s}^{-1}$ e numa distância máxima de penetração de $5 \mathrm{~mm}$; valores $\mathrm{L}^{*} \mathrm{e}$ b* foram medidos por reflectrometria, utilizando-se colorímetro da marca Minolta, modelo CR 300; para a medida do teor de amido (g de glicose por 100g) foi realizada extração e hidrólise segundo a técnica citada por ARÊAS \& LAJOLO (1980) e a determinação, segundo Somogy, modificada por NELSON (1944); para a análise sensorial foi realizado um teste massal com 50 avaliadores não treinados, foi avaliado o aspecto global do produto, com ênfase na aparência e na cor, de acordo com uma escala hedônica de 5 pontos, a saber: 1 - não consumível, 2 - limite de consumo, 3- limite de comercialização, 4 - bom e 5 - excelente.
As análises estatísticas foram realizadas com o auxílio do programa SISVAR(FERREIRA, 2000). Após análise de variância, as médias, quando significativas, foram comparadas, pelo teste de Tukey, a 1\% e 5\% de probabilidade.

\section{RESULTADOS E DISCUSSÃO}

As variáveis $\mathrm{pH}$, acidez titulável, sólidos solúveis e firmeza da mandioquinha-salsa minimamente processada não foram afetadas significativamente pelo fator atmosfera modificada, tampouco pelo tempo de armazenamento. Os valores médios de $\mathrm{pH}$, acidez titulável, sólidos solúveis e firmeza encontrados neste trabalho foram 6,79, 0,13\% de ácido málico, 4,04Bix e 5,17N, respectivamente. IEMMA (2001), avaliando o efeito da radiação gama na conservação da mandioquinha-salsa minimamente processada, embalada a vácuo e armazenada por 28 dias a $8^{\circ} \mathrm{C}$, encontrou valor médio de $\mathrm{pH}$ 6,50 para a mandioquinhasalsa não irradiada, valor próximo ao observado neste trabalho.

Houve interação significativa entre os fatores atmosfera modificada e tempo de armazenamento para a variável valor L*. A atmosfera modificada ativa, com injeção inicial de $5 \%$ de $\mathrm{O}_{2}+5 \%$ $\mathrm{CO}_{2}$ (ATM 2), determinou maior valor $\mathrm{L}^{*}$ para as mandioquinhas-salsa minimamente processadas no sexto e no décimo segundo dia de armazenamento quando comparada com a atmosfera modificada ativa, com injeção inicial de 2\% de $\mathrm{O}_{2}+10 \% \mathrm{CO}_{2}$ (ATM1) (Tabela 1), o que indica que as fatias de mandioquinhasalsa armazenadas sob aquela atmosfera apresentavam coloração mais clara, uma vez que essa variável demonstra quão claro (maior valor $L^{*}$ ) ou quão escuro (menor valor L*) é o produto. Nenhum efeito diferencial foi notado entre as atmosferas modificadas passiva (AMP) e ATM1, durante o período de armazenamento. IEMMA (2001) obteve valor L* médio de 80,3 para as mandioquinhas-salsa minimamente processadas não irradiadas e armazenadas sob refrigeração por 28 dias, conforme o observado neste trabalho.

Tabela 1 - Valores médios do valor L* de mandioquinhas-salsa 'Amarela de Senador Amaral' minimamente processadas e armazenadas sob atmosferas modificadas $\left(5^{ \pm} 1^{\circ} \mathrm{C}\right.$ e $\left.98 \%\right)$ por 15 dias.

\begin{tabular}{lcccccr}
\hline \multicolumn{5}{c}{ Tempos de armazenamento (dias) } \\
\hline & 0 & 3 & 6 & 9 & 12 & 15 \\
AMP & $79,7 \mathrm{a}$ & $81,5 \mathrm{a}$ & $78,7 \mathrm{ab}$ & $80,4 \mathrm{a}$ & $81,8 \mathrm{~b}$ & $81,7 \mathrm{a}$ \\
ATM1 & $79,7 \mathrm{a}$ & $82,2 \mathrm{a}$ & $77,6 \mathrm{~b}$ & $80,8 \mathrm{a}$ & $81,6 \mathrm{~b}$ & $82,4 \mathrm{a}$ \\
ATM 2 & $79,7 \mathrm{a}$ & $82,5 \mathrm{a}$ & $79,6 \mathrm{a}$ & $82,8 \mathrm{a}$ & $84,0 \mathrm{a}$ \\
\hline
\end{tabular}

Médias seguidas de mesma letra na coluna não diferem entre si pelo teste de Tukey, a $5 \%$.

Atmosferas modificadas passiva (AMP) e ativamente, com injeção inicial de $2 \%$ de $\mathrm{O}_{2}+10 \% \mathrm{CO}_{2}$ (ATM1) e de $5 \%$ de $\mathrm{O}_{2}+5 \% \mathrm{CO}_{2}$ (ATM 2). 
VITTI et al. (2003), trabalhando com beterraba minimamente processada em diferentes espessuras de corte armazenadas a $5^{\circ} \mathrm{C}$ durante 10 dias, e PILLON (2003), com cenouras minimamente processadas armazenadas sob ar, vácuo e atmosfera modificada e refrigeração por 21 dias, verificaram um esbranquiçamento do produto desde o início até o final do armazenamento, o que alguns autores denominam de White blush e atestam ser resultado da desidratação das células superficiais, devido aos danos causados pelo processamento (TATSUMI et al., 1993); para outros autores, o fato se deve à formação de lignina na superfície do corte (BOLIN \& HUXSOLL, 1991) ou então se deve a ambos ocorrendo concomitantemente (CINEROS-ZEVALLOS et al., 1995). Tal fato também pode ser atribuído à formação de traumatina, conhecida como hormônio do ferimento, que está envolvida no processo de divisão celular em resposta a ferimento (SIEDOW, 1991).

O valor $b^{*}$ foi influenciado significativamente apenas pelo fator atmosfera modificada. A ATM2 determinou maior média de valor b* em comparação às outras atmosferas (Tabela 2), o que indica que as mandioquinhas-salsa mantidas sob essa atmosfera apresentavam coloração mais amarela. IEMMA (2001) observou valor b* médio de 41,5 para as mandioquinhas-salsa minimamente processadas não irradiadas e armazenadas a $8^{\circ} \mathrm{C}$, por 28 dias, valor próximo ao encontrado neste trabalho.

A variável amido foi afetada significativamente apenas pelo fator atmosfera modificada. Os valores encontram-se na tabela 2. As mandioquinhas-salsa armazenadas sob ATM2 apresentaram maiores teores de amido, quando

Tabela 2 - Valores médios de valor b* $^{*}$ e amido de mandioquinhas-salsa 'Amarela de Senador Amaral' minimamente processadas e armazenadas sob atmosfera modificada $\left(5^{ \pm} 1^{\circ} \mathrm{C}\right.$ e $\left.98 \%\right)$ por 15 dias.

\begin{tabular}{lll}
\hline Tratamento & Valor b* & Amido \\
\hline AMP & $40,3 \mathrm{~b}$ & $21,5 \mathrm{~b}$ \\
ATM 1 & $40,4 \mathrm{~b}$ & $22,9 \mathrm{ab}$ \\
ATM 2 & $42,3 \mathrm{a}$ & $23,3 \mathrm{a}$ \\
\hline
\end{tabular}

Médias seguidas de mesma letra na coluna não diferem entre si pelo teste de Tukey, a 5\%.

Atmosferas modificadas passiva (AMP) e ativamente, com injeção inicial de $2 \%$ de $\mathrm{O}_{2}+10 \% \mathrm{CO}_{2}$ (ATM1) e de $5 \%$ de $\mathrm{O}_{2}+$ $5 \% \mathrm{CO}_{2}$ (ATM 2). comparadas àquelas armazenadas sob atmosfera modificada passiva. Não foi observada diferença estatística nos teores de amido entre as atmosferas modificadas ativamente. AATM2 reteve o teor de amido, o que é desejável, visto que a mandioquinha-salsa é uma excelente fonte de amido de boa digestibilidade. PEREIRA (1997), citando o valor nutricional da mandioquinha-salsa, apresentou valores médios de amido variando de $16,91-25,49 \%$, sendo os teores encontrados nas fatias de mandioquinha-salsa armazenadas, nas diferentes atmosferas, situados nessa faixa (Tabela 2).

\section{Análise sensorial:}

Houve interação significativa entre os fatores atmosfera modificada e tempo de armazenamento para as variáveis aparência e cor das mandioquinhas-salsa minimamente processadas. As atmosferas AMP e ATM1 não diferiram entre si ao longo do armazenamento, apresentando notas de aparência superiores às dos produtos minimamente processados sob ATM2 no nono e no décimo segundo dia de armazenamento. Em relação à cor, as fatias de mandioquinha-salsa armazenadas sob ATM1 apresentaram notas superiores às mantidas sob ATM2 no terceiro e no nono dia. Ao final do armazenamento, pôde-se observar que não ocorreu depreciação da cor e nem da aparência, estando as notas próximas do conceito "bom" (4), independentemente da atmosfera utilizada no armazenamento (Tabela 3)

A qualidade sensorial para os produtos minimamente processados se refere, dentre outros aspectos, à aparência e cor aceitáveis e atrativas, que despertem a atenção do consumidor, levando-o a escolher esse produto (SANTOS \& VALLE, 2005). A aparência do produto exerce papel fundamental na decisão de compra do consumidor, uma vez que é por meio da observação desse parâmetro que o consumidor seleciona, escolhe e consome o alimento (DELIZA, 2000).

\section{CONCLUSÕES}

A atmosfera modificada passiva, aliada à refrigeração e a boas práticas de fabricação, é suficiente para prolongar a vida útil de mandioquinha-salsa minimamente processada por 15 dias, preservando os atributos de qualidade avaliados.

Diante da avaliação sensorial realizada, a aparência e a cor das fatias de mandioquinha-salsa mantiveram-se aceitáveis para o consumo até o final do período de armazenamento. 
Tabela 3 - Valores médios de aparência e cor de mandioquinhas-salsa 'Amarela de Senador Amaral' minimamente processadas e armazenadas sob atmosferas modificadas $\left(5 \pm 1^{\circ} \mathrm{C}\right.$ e $\left.98 \%\right)$ por 15 dias.

\begin{tabular}{|c|c|c|c|c|c|c|}
\hline & \multicolumn{6}{|c|}{ Tempo de armazenamento (dias) } \\
\hline & 0 & 3 & 6 & 9 & 12 & 15 \\
\hline AMP & 4,63 a & 3,81 a & 3,44 a & 3,81 a & 3,69 a & $3,94 \mathrm{a}$ \\
\hline ATM 1 & 4,63 a & 4,06 a & $3,88 \mathrm{a}$ & 3,38 a & $3,81 \mathrm{a}$ & $3,88 \mathrm{a}$ \\
\hline ATM 2 & 4,63 a & 3,68 a & $4,06 \mathrm{a}$ & $2,44 \mathrm{~b}$ & $3,25 b$ & $4,19 \mathrm{a}$ \\
\hline AMP & 4,69 a & $3,75 \mathrm{ab}$ & $3,44 \mathrm{a}$ & $4,00 \mathrm{a}$ & 3,50 a & $3,94 \mathrm{a}$ \\
\hline ATM1 & 4,69 a & $4,25 \mathrm{a}$ & $3,88 \mathrm{a}$ & 3,50 a & 3,63 a & $4,00 \mathrm{a}$ \\
\hline ATM 2 & 4,69 a & $3,44 \mathrm{~b}$ & 3,94 a & $2,75 \mathrm{~b}$ & 3,13 a & $4,06 \mathrm{a}$ \\
\hline
\end{tabular}

Médias seguidas de mesma letra na coluna não diferem entre si pelo teste de Tukey, a 5\%. Atmosferas modificadas passiva (AMP) e ativamente, com injeção inicial de $2 \%$ de $\mathrm{O}_{2}+10 \% \mathrm{CO}_{2}$ (ATM1) e de $5 \%$ de $\mathrm{O}_{2}+5 \% \mathrm{CO}_{2}$ (ATM 2).

\section{REFERÊNCIAS}

ARÊAS, J.A.G.; LAJOLO, F.M. Determinação enzimática específica de amido, glicose, frutose e sacarose em bananas préclimatéricas e climatéricas. Anais de Farmácia e Química de São Paulo,, v.20, n.1/2, p.307-318, 1980.

ARRUDA, M.C. et al. Conservação de melão rendilhado minimamente processado sob atmosfera modificada ativa. Ciência e Tecnologia de Alimentos, v.24, n.1, p.53-58, 2004. Disponível em: <http:// www.scielo.br/scielo.php?script=sci_arttext\&pid=S010120612004000100011\&lng=pt\&nrm=iso\&tlng=pt>. Acesso em: 14 abr. 2009. doi: 10.1590/S0101-20612004000100011.

ASSOCIATION OF OFFICIAL ANALYTICAL CHEMISTRY. Official methods of analysis of the Association of Official Analytical Chemistry. 12.ed. Washington, 1992. 1015p.

BEAUDRY, R. Responses of horticultural commodities to low oxygen: limits to the expanded use of modified atmosphere packaging. HortTechnology, v.10, p.491-500, 2000.

BOLIN, H.R.; HUXSOLL, C.C. Control of minimally processed carrot (Daucus carota) surface discoloration caused by abrasion peeling. Journal of Food Science, v.56, n.2, p.416-418, 1991. Disponível em: <http://www3.interscience.wiley.com/journal/ 119344765/abstract?CRETRY=1\&SRETRY=0>. Acesso em 25 ago. 2006. doi: 10.1111/j.1365-2621.1991.tb05294.x

CARLIN, F. et al. Microbiological spoilage of fresh ready-touse carrots. Science des Aliments, Lavoisier, v.9, p.371386, 1989.

CINEROS-ZEVALLOS, L. et al. Mechanism of surface white discoloration of peeled (minimally processed) carrots during storage. Journal of Food Science, v.60, n.2, p.320-324, 1995. Acesso em 26 Ago. 2006. doi: 10.1111/j.13652621.1995.tb05664.x

DAREZZO, H.M. Processamento mínimo de alface (Lactuca sativa L.). In: ENCONTRO NACIONAL SOBRE PROCESSAMENTO MÍNIMO DE FRUTAS E HORTALIÇAS, Viçosa, 2000. Palestras... Viçosa: UFV, 2000. p.117-124.
DELIZA, R. Importância da qualidade sensorial em produtos minimamente processados. In: ENCONTRO NACIONAL SOBRE PROCESSAMENTO MÍNIMO DE FRUTAS E HORTALIÇAS, 2000, Viçosa, MG. Palestras... Viçosa: UFV, 2000. p.73-74.

FERREIRA, D. F. Análises estatísticas por meio do SISVAR para windows versão 4.0. In: REUNIÃO ANUAL DA REGIÃO BRASILEIRA DASOCIEDADE INTERNACIONAL DE BIOMETRIA, 45., 2000, São Carlos. Resumos... São Carlos, SP: UFSCar, 2000. p.235.

HEIMDAL, H. et al. Biochemical changes and sensory quality of shredded and MA-packaged iceberg lettuce. Journal of Food Science, v.60, n.6, p.1265-1268, 1995. Disponível em: <http://www3.interscience.wiley.com/journal/119237749/ abstract>. Acesso em 26 ago. 2006. doi: 10.1111/j.13652621.1995.tb04570.x

IEMMA, J. Efeito da radiação gama na conservação da mandioquinha-salsa (Arracacia xanthorrhiza Bancroft) minimamente processada e embalada a vácuo. 2001. 58f. Dissertação (Mestrado em Ciências) - CENA/USP, Piracicaba, SP.

INSTITUTO ADOLFO LUTZ. Normas analíticas, métodos químicos e físicos para análise de alimentos. 3.ed. São Paulo: Instituto Adolfo Lutz, 1985. V.1, 533p.

KADER, A. et al. Modified atmosphere packaging of fruits and vegetables. Critical Reviews in Food Science and Nutrition,v.28, p.1-30, 1989.

KAYS, S.J. Postharvest physiology of perishable plant products. New York,: Van Nostrand-Reinhold, 1991. 532p.

LOPEZ-GALVEZ, G. et al. Quality changes in packaged salad products during storage. Zeitschrift für Lebensmitteluntersuchung und Forschung A, v.205, p.64-72, 1997.

MATHOOKO, F. Regulation of respiratory metabolism in fruits and vegetables by carbon dioxide. Postharvest Biology andTechnology, v.9, p.247-264, 1996. Disponível em: <http:// www.sciencedirect.com/science?_ob=ArticleURL\&_udi=B6TBJ3RG551D-W\&_user $=686380 \&$ \& coverDate $=12 \% 2$ F $31 \%$ 
2F1996\&_rdoc $=1 \&$ \&_fmt=high\&_orig=browse\&_srch=doc $>$. Acesso em 14 abr. 2009. doi: 10.1016/S0925-5214(96)00019-1.

MORETTI, C.L.; ARAÚJO, A.L. Processamento mínimo de mandioquinha-salsa. Brasília: Embrapa Hortaliças, 2001. 8p. (Comunicado Técnico, 17).

NELSON, N.A. Photometric adaptation of Somogyi method for the determination of glucose. Journal of Biological Chemistry, v.153, n.2, p.375-380, 1944.

PEREIRA, A.S. Valor nutritivo da mandioquinha-salsa. Informe Agropecuário, Belo Horizonte, v.19, n.190, p.11-12, 1997.

PILLON, L. Estabelecimento da vida útil de hortaliças minimamente processadas sob atmosfera modificada e refrigeração. 2003. 111p. Dissertação (Mestrado em Ciências) ESALQ, Piracicaba, SP.

PIROVANI, M.E. Quality of minimally processed letucce as influenced by packaging and chemical treatment. Journal of Food Quality, v.22, p.475-484, 1998. Disponível em: <http:/ /www3.interscience.wiley.com/journal/119117454/issue>. Acesso em 31 mai. 2007. doi: 10.1111/j.1745-4557.1998.tb00537.x.

SANTOS, H. P. dos; VALLE, R.H.P. do. Influência da sanificação sobre a qualidade de melão 'Amarelo' minimamente processado: parte II. Ciência e Agrotecnologia, v.29, n.5, p.1034-1038, 2005.

SIEDOW, J.N. Plant lipoxigenase: struture and function. Annual Review of Plant Physiology and Plant Molecular Biology, v.42, p.145-188, 1991. Disponível em: <http:// arjournals.annualreviews.org/doi/pdf/10.1146/ annurev.pp.42.060191.001045>. Acesso em 14 abr. 2009. doi: 1040-2519/91/0601-0145\$02.00.

TATSUMI, Y. et al. Sodium chlorine treatment or waterjet slicing effects on white tissue development of carrot sticks. Journal of Food Science, v.58, n.6, p.1390-1392, 1993. Disponível em: <http://www3.interscience.wiley.com/journal/ 119293635/issue>. Acesso em: 26 ago. 006. doi: 10.1111/ j.1365-2621.1993.tb06189.x.

VITTI, M.C.D. et al. Comportamento da beterraba minimamente processada em diferentes espessuras de corte. Horticultura Brasileira, v.21, n.4, p.623-626, 2003. Disponível em: <http:/ /www.scielo.br/pdf/hb/v21n4/19425.pdf>. Acesso em 14 abr. 2009. doi:10.1590/S0102-05362003000400009.

WATKINS, C. Responses of horticultural commodities to high carbon dioxide as related to modified atmosphere packaging. HortTechnology, v.10, p.501-506, 2000. 